\title{
Cuidar a enfermos crónicos en condiciones de pobreza: entre la dificultad y la invisibilidad
}

\author{
La invisibilidad del cuidado a los \\ enfermos crónicos: un estudio \\ cualitativo en el barrio de Oblatos.
}

ROBLES-SILVA, Leticia.

Guadalajara: Editorial Universitaria, 2007. $390 \mathrm{p}$.

El libro La invisibilidad del cuidado a los enfermos crónicos: un estudio cualitativo en el barrio de Oblatos es el resultado de una investigación etnográfica, realizada en un sector popular en una ciudad mexicana. Su autora, Leticia Robles Silva, presenta una propuesta para analizar las prácticas y experiencias cotidianas de cuidadoras de enfermos crónicos, y analizar el fenómeno del cuidado desde la perspectiva de sus actores: las mujeres. Es decir, en este libro se recupera la experiencia de cuidar a un enfermo crónico desde la perspectiva de la cuidadora.

Coloquialmente decimos que desde que nacemos hasta que morimos somos cuidados por alguien y además, a lo largo de nuestra vida, en más de una ocasión, estaremos en contacto con el cuidado ya sea por familiares, amigos o conocidos, o más aún, nosotros mismos vamos a llevar a cabo el "arduo" trabajo de cuidar. El cuidado no sólo es una situación de la que nadie escapa a lo largo de la vida; sino también es un fenómeno social siempre presente a nuestro alrededor. El cuidado, afirma la autora, incluye todo aquello que se hace para ayudar al otro a satisfacer sus necesidades básicas, desarrollar o mantener sus capacidades y habilidades necesarias para su funcionamiento en la sociedad, y para evitar o aliviar el dolor y el sufrimiento de una manera atenta, respetuosa y sensible; en pocas palabras, cuidar es un trabajo inevitable y nada sencillo.

La autora argumenta dos circunstancias por las cuales es pertinente estudiar el cuidado: el aumento de las enfermedades crónicas y el creciente fenómeno del envejecimiento. En México, como en otros países latinoamericanos, el número de personas que padecen una o más enfermedades crónicas como diabetes, hipertensión o cáncer es cada vez mayor. Aunado a la enfermedad crónica, el fenómeno del envejecimiento es cada día más una realidad observable, cada vez hay menos niños y más ancianos en el mundo. Ambos fenómenos no sólo afectan al individuo que enferma o envejece, sino también a otro número igual o mayor de familiares que se ven obligados a cuidarlos. Varios millones de personas en el mundo han pasado a ser cuidadoras de algún familiar enfermo o viejo, sumándose a los millones de enfermos y ancianos afectados por ambos fenómenos. La importancia numérica de la enfermedad crónica y el envejecimiento no es un asunto exclusivo de enfermos y ancianos sino también de cuidadoras. Sin cuidadoras no podría sobrevivir enfermo alguno, argumenta la autora.

En su obra, la autora delimita su objeto de estudio al cuidado de enfermos crónicos, realizando un invaluable análisis en el espacio del hogar, al demostrar cómo el cuidado involucra trabajo y no únicamente sentimientos, y cómo es un campo de poder y dominio sobre la mujer ya que, a pesar de ser un trabajo que 
conlleva actividades arduas y complejas, es un trabajo femenino e invisible.

La invisibilidad del cuidado a los enfermos crónicos: un estudio cualitativo en el barrio de Oblatos es una obra que no puede dejar de ser leída, en la cual se buscan explicaciones sobre la enfermedad, los enfermos, su familia y sus cuidadoras, que van más allá de los acercamientos tradicionales en este campo con conceptos tales como "redes sociales" y "apoyo social"; es decir, es un esfuerzo por aproximarse a un fenómeno social invisible, situándose a nivel microsocial para analizar el cuidado desde una perspectiva cultural y de género en aras de ofrecer una explicación antropológica del cuidado como una vía analíitica para entender la valoración del cuidado como una carga pesada y, al mismo tiempo, dilucidar el funcionamiento de un dispositivo de control social para retener a las mujeres en el cuidado, es decir, en su papel de cuidadoras.

¿Cómo funciona el cuidado? Es la pregunta de investigación que orienta el análisis a lo largo del libro. Pero también la autora se plantea el reto de entender por qué se convierte en una carga pesada a través de analizar el contenido y la organización del cuidado, y dilucidar posteriormente los mecanismos que garantizan la permanencia de esa mujer en el cuidado. Cabe señalar que la construcción empírica exigió cuatro años de trabajo de campo.

El objetivo principal de La invisibilidad del cuidado a los enfermos crónicos: un estudio cualitativo en el barrio de Oblatos y la razón por la que debe ser leído tanto por profesionales de la salud como por enfermos y por supuesto por cuidadoras, es para comprender ese mundo invisible del cuidado y descubrir la respuesta a las preguntas: ¿Cuáles son esas condiciones sociales que explican la valoración del cuidado como una carga pesada? Y ¿Por qué a pesar de "casi" todo, las mujeres que son cuidadoras no abandonan el cuidado?

El libro está dividido en tres partes de una manera didáctica, lo cual hace que cualquiera disfrute a cada momento de su lectura y se sienta llevado de la mano para entender cuestiones que van desde la complejidad de la problemática del cuidado, el contexto en el que se desarrolla dicha problemática, las particulares con que cada cuidadora y enfermo viven la enfermedad, los conceptos básicos sobre el cuidado y cómo se hizo el estudio, hasta los enriquecedores resultados de una investigación bien realizada.

En la primera parte de la obra se encuentran dos capítulos donde se presenta el problema teórico sobre el cuidado, así como su acercamiento metodológico, describiendo no sólo las entrevistas a profundidad, sino también su proceso de registro, la elaboración de notas de campo, la utilización de fuentes secundarias, la organización del material, la observación y los distintos análisis realizados. La segunda parte se compone de dos capítulos que describen el contexto social en el que vivían las cuidadoras y los enfermos; donde la autora nos hace viajar hasta la época de la Colonia al oriente de la ciudad de Guadalajara, México, para situarnos en los orígenes de Oblatos, el lugar donde se hizo el estudio, recreando a sus primeros habitantes, sus primeras construcciones y su economía, para después introducirnos en el contexto social actual de la vida de las cuidadoras de esta obra, y ofrecernos una descripción puntual de cómo es que vivían los enfermos con la diabetes a lo largo del tiempo. Finalmente la tercera parte está compuesta por cuatro capítulos que dan respuesta a las dos preguntas centrales de investigación planteadas por la autora.

En esta tercera parte, se dedica un capítulo a explicar el proceso de designación de la cuidadora. En el siguiente capítulo se analizan el contenido y la organización del cuidado, lo cual incluye una pormenorizada descripción de cuáles son las acciones de cuidado y cómo se organizan en líneas de cuidado en el contexto de la vida cotidiana, familiar y social de la cuidadora. En otro capítulo se desglosan las trayectorias del cuidado mostrando como el cuidado se transforma a lo largo del tiempo; y en el último capítulo se describen el contenido y el funcionamiento del panóptico, utilizando el concepto de Foucault, para explicar por qué no se abandona el cuidado a pesar de ser una carga pesada, y cómo existe un proceso de devaluación de la cuidadora. La autora nos ofrece evidencias de cómo ninguna de las cuidadores abandonó su rol a pesar de expresar deseos por "abandonarlo todo", y su permanencia la explica a partir de la existencia de un panóptico en torno al cuidado, el cual funciona como un dispositivo disciplinario, para someter a la cuidadora a las normas morales del cuidado. Pero en las cuidadoras de Oblatos estuvo presente también la resistencia, encaminada a sobrevivir hoy y no a transformar el sistema de dominación del cuidado. Al final la obra cuenta con una sección interesante, donde la autora, de una manera integradora y precisa, resume los hallazgos más sobresalientes de su investigación y ofrece algunas reflexiones sobre el futuro del cuidado en Oblatos. 
El libro cumple con su cometido, hacer visibles varios rasgos invisibles del cuidado, y ofrecer nuevos datos para abrir el rumbo a nuevas investigaciones. Asimismo nos convence y nos invita a la reflexión de qué es el cuidado y cómo se otorga, pero también de qué es ser pobre y vivir en la pobreza cuando se cuida a un enfermo crónico. Nos hace recapacitar de que, a pesar de los adelantos tecnológicos, la presencia de una cuidadora es indispensable si se quiere sobrevivir ante las crisis del padecimiento $o$ ante las discapacidades sufridas por la vejez y la enfermedad crónica. Y finalmente, por esas ventajas tecnológicas, el libro puede ser adquirido en la editorial por compra en línea. Así que no tendrá pretexto para no leerlo.

La invisibilidad del cuidado a los enfermos crónicos: un estudio cualitativo en el barrio de Oblatos es una clara muestra de excelencia académica; la investigación que le dio origen fue reconocida en México con el Premio Fray Bernardino de Sahagún por el Instituto Nacional de Antropología e Historia en el año 2002.

María Guadalupe Ramírez-Contreras Universidad de Guadalajara, México 